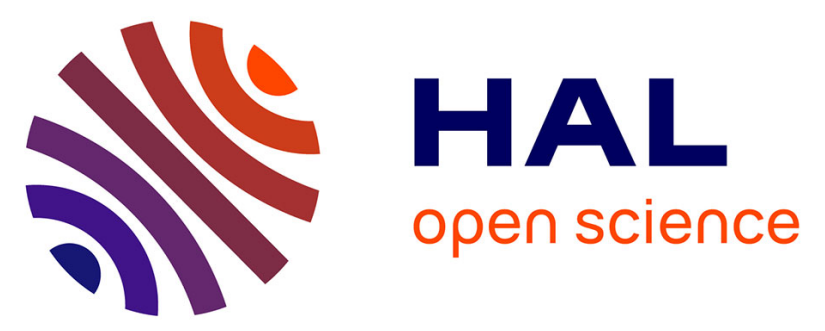

\title{
Development and validation of a minimal growth medium for recycling Chlorella vulgaris culture
}

F. Hadj-Romdhane, P. Jaouen, Jeremy Pruvost, D. Grizeau, G. van Vooren, P. Bourseau

\section{- To cite this version:}

F. Hadj-Romdhane, P. Jaouen, Jeremy Pruvost, D. Grizeau, G. van Vooren, et al.. Development and validation of a minimal growth medium for recycling Chlorella vulgaris culture. Bioresource Technology, 2012, 123, pp.366-374. 10.1016/j.biortech.2012.07.085 . hal-02534145

\section{HAL Id: hal-02534145 \\ https://hal.science/hal-02534145}

Submitted on 10 Apr 2020

HAL is a multi-disciplinary open access archive for the deposit and dissemination of scientific research documents, whether they are published or not. The documents may come from teaching and research institutions in France or abroad, or from public or private research centers.
L'archive ouverte pluridisciplinaire HAL, est destinée au dépôt et à la diffusion de documents scientifiques de niveau recherche, publiés ou non, émanant des établissements d'enseignement et de recherche français ou étrangers, des laboratoires publics ou privés. 


\title{
Development and validation of a minimal growth medium for recycling Chlorella vulgaris culture
}

\author{
F. Hadj-Romdhane ${ }^{a}$, P. Jaouen ${ }^{a}$, J. Pruvost ${ }^{a}$, D. Grizeau ${ }^{a}$, G. Van Vooren ${ }^{a}$, P. Bourseau ${ }^{a, b, *}$ \\ a Université de Nantes, CNRS, GEPEA UMR-CNRS 6144, boulevard de l'Université, CRTT-BP 406, 44602 Saint-Nazaire Cedex, France \\ ${ }^{\mathrm{b}}$ Université de Bretagne Sud, LIMATB, rue de Saint-Maudé, BP 92116, 56321 Lorient Cedex, France
}

\begin{abstract}
A B S T R A C T
When microalgae culture medium is recycled, ions (e.g. $\mathrm{Na}^{+}, \mathrm{K}^{+}, \mathrm{Ca}^{2+}$ ) that were not assimilated by the microalgae accumulate in the medium. Therefore, a growth medium (HAMGM) was developed that included ions that were more easily assimilated by Chlorella vulgaris, such as ammonium one $\left(\mathrm{NH}_{4}{ }^{+}\right)$. Recycling performance was studied by carrying out 8-week continuous cultivation of $C$. vulgaris with recycled HAMGM medium. No loss of biomass productivity was observed compared to culture in a conventional medium, and accumulation of ions over time was negligible.
\end{abstract}

\section{Introduction}

Microalgae exhibit broad biodiversity and have been used for many decades as an important source of specific metabolites, such as pigments, antioxidants and polysaccharides. Their main current applications are biomass production for feed (Pulz and Gross, 2004), aquaculture (Muller-Feuga, 2000; Spolaore et al., 2006) and food supplements, with many other developments in wastewater treatment, industrial $\mathrm{CO}_{2}$ fixation (Benemann, 2009; Çetinkaya Dönmez et al., 1999; Mata et al., 2010) and future potential applications for energy-related purposes (Chisti, 2007; Harun et al., 2010) and for life support systems in space (Rossi et al., 2008).

Microalgae cultures are run in various types of cultivation systems (open ponds, raceways, and closed photobioreactors) depending on environmental conditions and applications. For large-scale continuous cultures, open ponds or raceways are widely used, due to their low cost (Borowitzka, 1999). Such extensive systems can present very high culture volumes (up to several thousand cubic meters) with biomass concentrations generally below $1 \mathrm{~kg} \mathrm{~m}^{-3}$. Recycling culture medium could therefore save much water, reduce nutrient inputs, and lower the economic and ecological impacts of the process. However, recycling culture medium can have negative effects on biomass growth due to the accumulation of metabolites (lipids, polysaccharides, proteins or other nitrogenous entities) released during growth when physiological stress or cell lysis occur (Fogg, 1966; 1971), in particular in cultures at high biomass concentrations (Richmond, 2004). Thus, inhibitory and toxic effects of lipids have been described (Ikawa, 2004; Wu et al., 2006), and Robertson and Fong, 1940 reported the release of a substance by $C$. vulgaris derived from fatty acid photo-oxidation, chlorellin, which depressed microalgal growth.

In addition to excreted metabolites, minerals can also accumulate during growth medium recycling. This is especially the case for counter ions of $\mathrm{NH}_{4}{ }^{+}, \mathrm{CO}_{3}{ }^{2-}, \mathrm{PO}_{4}{ }^{3-}$ in salts such as $\mathrm{NH}_{4} \mathrm{Cl}, \mathrm{NaHCO}_{3}$ and $\mathrm{KH}_{2} \mathrm{PO}_{4}$ which are not, or only poorly assimilated by the 
microalgae. These ions accumulate in the medium during recycling, leading to a gradual change in the composition and in the physical-chemical properties of the growth medium.

The present study investigates accumulation and impacts of mineral matter during medium recycling, obtained at each biomass harvest. The rapid increase in osmolality when recycling conventional medium was confirmed. A highly assimilable minimal growth medium (HAMGM) was developed for C. vulgaris. Algae growth in this medium was compared with that in a conventional medium. The ability of the HAMGM medium to maintain stable long-term production with total medium recycling and reduced ion accumulation was also verified.

\section{Materials and methods}

\subsection{Strain and medium}

The strain used in this study was C. vulgaris (211/19 SAG), chosen for its ability to assimilate both ammonium $\left(\mathrm{NH}_{4}{ }^{+}\right)$and nitrate $\left(\mathrm{NO}_{3}{ }^{-}\right)$as nitrogen source, with a preference for ammonium (Reisner et al., 1960; Schuler et al., 1952). The autotrophic Sueoka medium (Sueoka, 1960) described by Harris (2009) was taken as a reference (conventional growth medium). The composition was adapted to reach a biomass concentration of up to $2.5 \mathrm{~g} \mathrm{~L}^{-1}$ with no mineral limitation. The composition of the conventional medium was: $\left(\mathrm{mmol} \mathrm{L}^{-1}\right)$ : $\mathrm{NH}_{4} \mathrm{Cl}, 27.1 ; \mathrm{MgSO}_{4} \cdot 7 \mathrm{H}_{2} \mathrm{O}, 1.14 ; \mathrm{KH}_{2} \mathrm{PO}_{4}$, 4.48; $\mathrm{CaCl}_{2} \cdot 2 \mathrm{H}_{2} \mathrm{O}, 0.34 ; \mathrm{NaHCO}_{3}, 20.0$ and $1 \mathrm{~mL} \mathrm{~L}^{-1}$ of Hutner's trace element solution (Hutner et al., 1950). The growth medium was prepared using distilled water. For all cultures in PBR, pH and temperature were controlled at 7.5 and $25^{\circ} \mathrm{C}$.

\subsection{Airlift photobioreactor}

Experiments were conducted in a flat panel airlift photobioreactor (PBR) (Fig. 1) with an optical path $(e)$ of $0.03 \mathrm{~m}$, a working volume $(V)$ of $1 \mathrm{~L}$, and a specific illuminated surface area $\left(a_{\text {light }}\right)$ of $33.3 \mathrm{~m}^{-1}$ (for a flat PBR: $a_{\text {light }}=1 / e$ ). The PBR was built of transparent material, except for its rear side which was stainless steel (type 316L).

The PBR was illuminated with a panel of 80 white LEDs (lightemitting diodes, P4 Cool White, Seoul SemiConductor). This collimated light source was placed in front of the illuminated surface and allowed an incident photon flux density (PFD, noted $q_{0}$ ) of up to $2000 \mu \mathrm{mol} \mathrm{m}^{-2} \mathrm{~s}^{-1}$, by varying the potential applied to the light source. The PFD value was $270 \mu \mathrm{mol} \mathrm{m}^{-2} \mathrm{~s}^{-1}$. The PFD was measured with a quantum sensor (LI-250A, LI-COR, Lincoln, NE). The mean PFD on the PBR front face was determined by averaging 12 different measurement points inside the PBR, on the transparent front to take into consideration light attenuation across the optical surface.

The culture was mixed by sterile air injection at the bottom of the PBR. The $\mathrm{pH}$ and temperature were controlled by a $\mathrm{pH} /$ temperature probe (sensor Mettler Toledo SG 3253) monitored by the acquisition software LabVIEW. When the $\mathrm{pH}$ was higher than the set point $(\mathrm{pH}>7.5), \mathrm{CO}_{2}$ was injected by activating a solenoid valve. The culture medium was cooled $\left(25^{\circ} \mathrm{C}\right)$ by a blower fixed on the rear side of the PBR.

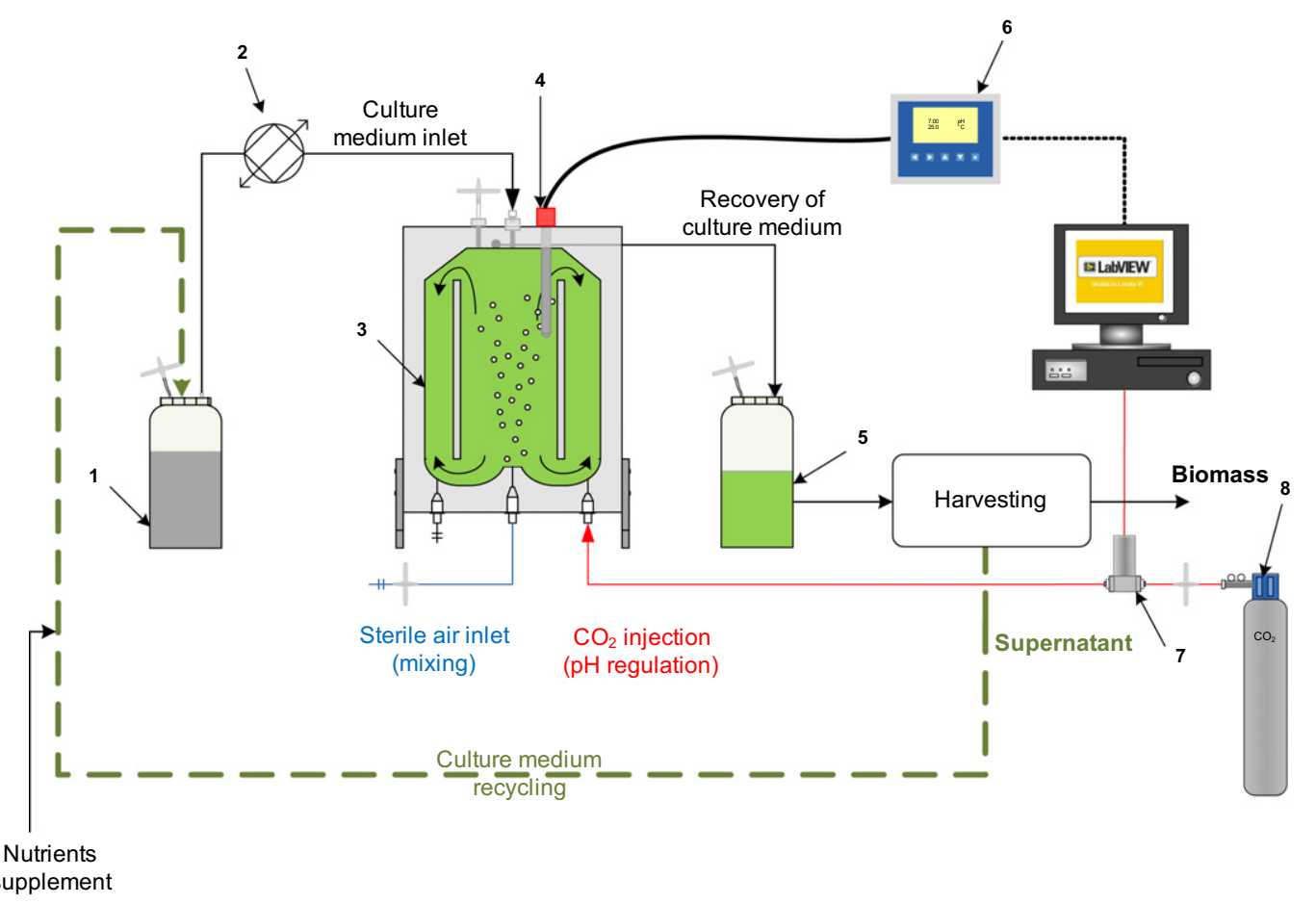
1. Culture medium feed bottle $\left(V_{F}=4 \mathrm{~L}\right)$
4. $\mathrm{pH}$ and temperature probe
7. Solenoid valve
2. Metering pump Stepdos ${ }^{\circledR}$
5. Culture medium harvesting bottle $\left(V_{H}=1.52 \mathrm{~L}\right)$
8. Bottle of $\mathrm{CO}_{2}$
3. Airlift PBR $(V=1 \mathrm{~L})$
6. $\mathrm{pH}$ and temperature transmitter

Fig. 1. Schematic diagram of pilot plant for the continuous culture of Chlorella vulgaris. The PBR used for these experiments is a flat-panel airlift ( $3 \mathrm{~cm}$ optical path, $\left.a_{\text {light }}=33 \mathrm{~m}^{-1}\right)$, with regulated $\mathrm{pH}$ and temperature $\left(q_{0}=270 \mu \mathrm{mol} \mathrm{m}^{-2} \mathrm{~s}^{-1}, \mathrm{pH}=7.5, T=25^{\circ} \mathrm{C}\right)$. The dashed line represents the medium recycling step. 
The PBR was operated in a continuous mode with a constant dilution rate controlled daily by measuring the flow rate. A metering pump (Stepdos ${ }^{\circledR}$ 08/RC, KNF Neuberger) was used to control the flow rate of the inlet culture medium. Algae were recovered by culture medium overflowing into a harvesting bottle.

\subsection{Experimental set-up and recycling protocol}

The experimental set-up is presented in Fig. 1. Its purpose was to observe and identify possible drifts in biomass quality and productivity due to mineral matter accumulation during medium recycling. A protocol representative of real operating conditions was applied. Culture medium was fed into the PBR at a flow rate of $Q_{0}=0.432 \mathrm{~L} \mathrm{day}^{-1}\left(5 \times 10^{-9} \mathrm{~m}^{3} \mathrm{~s}^{-1}\right)$ corresponding to a retention time of 2.31 days (for a PBR volume of $1 \mathrm{~L}$ ). The culture was continuously harvested by overflowing and stored for 3.5 days before treatment in an illuminated closed bottle mixed twice a day. A specific experiment was performed, to check the absence of biological degradation of the culture during storage: a culture volume was maintained for 4 days in the same conditions of illumination and mixing and a daily sampling showed that no change in biomass quality and no organic matter excretion in the supernatant occurred. Indeed, chlorophyll content and organic matter release into the supernatant remained constant $([$ Chl-tot $]=5.79 \pm 0.12 \%$ $\left.(\mathrm{w} / \mathrm{w}), C O D=65.7 \pm 7.5 \mathrm{mg} \mathrm{L}^{-1}\right)$, as well biomass concentration $\left(C_{X}=2.15 \pm 0.03 \mathrm{~g} \mathrm{~L}^{-1}\right)$, proving that changes in the culture in the storage bottle were negligible.

Every 3.5 days (twice a week), the entire stored harvested culture $\left(V_{\mathrm{H}}=1.52 \mathrm{~L}\right)$ was centrifuged $\left(17,600 \mathrm{~g}, 15 \mathrm{~min}, 15^{\circ} \mathrm{C}\right)$ to separate the supernatant from the biomass. Consumption of the main nutrients was determined by ionic chromatography and then, the supernatant was replenished with $\mathrm{NH}_{4} \mathrm{Cl}, \mathrm{MgSO}_{4}, \mathrm{KH}_{2} \mathrm{PO}_{4}$, and $\mathrm{NaHCO}_{3}$ as sources of main nutrients (respectively nitrogen, sulfur, phosphorus and carbon), at the same time supplying the needs for magnesium and potassium. The supernatant was finally reintroduced with no further treatment into the feeding medium bottle. A sufficient volume of feeding medium $\left(V_{\mathrm{F}}=4 \mathrm{~L}\right)$ was chosen to avoid interruption in the PBR feeding. The renewing time of the feeding bottle $\tau_{\mathrm{F}}\left(\tau_{\mathrm{F}}=\mathrm{V}_{\mathrm{F}} / \mathrm{Q}_{0}\right)$ was equal to 9.26 days of $(4 \mathrm{~L} /$ $0.432 \mathrm{~L} \mathrm{day}^{-1}$ ) meaning that the volume of the feeding bottle was totally renewed every 9.3 days. The recycling protocol thus allowed the PBR to be run in continuous mode with permanent feeding in recycled medium, allowing a quasi-steady-state to be obtained enabling the investigation of the system's stability.

\subsection{Analytical methods}

\subsubsection{Biomass dry weight concentration}

Biomass dry weight concentration was determined gravimetrically. The sample was filtered through a rinsed glass-fiber filter (Whatman GF/F), pre-dried and weighed. The filter was dried for $24 \mathrm{~h}$ at $105^{\circ} \mathrm{C}$, cooled in a desiccator and weighed again. Analyses were performed in triplicate and the results are given as the average of the three measurements. Measurement of the biomass dry weight concentration enabled determination of biomass productivity $P_{X}$ as:

$P_{X}=C_{X} \cdot D$,

with $D=Q / V=1 / \tau$, the dilution rate fixed by the feeding flow rate (with $Q$ the feeding flow rate of medium, $V$ the PBR volume and $\tau$ the residence time of the culture in the PBR).

\subsubsection{Pigment content}

Pigments were extracted with pure methanol. A volume of $250 \mu \mathrm{L}$ of culture was introduced into a 2-mL Eppendorf tube, and $1250 \mu \mathrm{L}$ of methanol was added. The tube was incubated for
$45 \mathrm{~min}$ at $45^{\circ} \mathrm{C}$ and centrifuged at $12,100 \mathrm{~g}$ for $5 \mathrm{~min}$. The supernatant was analyzed with a UV-Vis spectrophotometer (Perkin-Elmer, Lambda 10). Chlorophyll a (Chl-a), chlorophyll b (Chl-b) and total chlorophylls (Chl-t) were determined according to Ritchie (2006) as:

$$
\begin{aligned}
& {[\text { Chl-a }] \mu \mathrm{g} \mathrm{mL}^{-1}=-8.0962 \times A_{652}+16.5169 \times A_{665}} \\
& {[\text { Chl-b }] \mu \mathrm{g} \mathrm{mL}{ }^{-1}=27.4405 \times A_{652}+12.1688 \times A_{665}} \\
& {[\text { Chl-t }] \mu \mathrm{g} \mathrm{mL}^{-1}=19.3443 \times A_{652}+4.3481 \times A_{665}}
\end{aligned}
$$

The analysis was performed in triplicate.

\subsubsection{Elementary analysis}

A volume of culture medium containing at least $30 \mathrm{mg}$ of dry matter was centrifuged at $3,900 \mathrm{~g}$ and washed three times with distilled water to remove salt residues. The sample was lyophilized $\left(\mathrm{RP} 2 \mathrm{~V}^{\circledR}\right.$ freeze dryer, $T=-42^{\circ} \mathrm{C}, P=0.005$ bar). Elementary composition analysis was performed by the CNRS central analysis service (Solaize, France). Carbon, hydrogen, nitrogen and sulfur contents were determined by total combustion of the sample at $1500{ }^{\circ} \mathrm{C}$ (for $\mathrm{C}$ and $\mathrm{H}$ ), $1050^{\circ} \mathrm{C}(\mathrm{N})$ or $1250^{\circ} \mathrm{C}(\mathrm{S})$ under a controlled stream of oxygen and helium. Oxygen content was determined by pyrolysis at $1080^{\circ} \mathrm{C}$ under a nitrogen stream. The resulting gases were quantified by a thermal-conductivity sensor or by an infrared specific detector (LECO, SC-144). Elementary composition gave the overall stoichiometry of the biomass, and an estimate of the nutrient requirement (Pruvost et al., 2009).

\subsubsection{Ion concentrations}

The $\mathrm{PO}_{4}{ }^{3-}, \mathrm{SO}_{4}{ }^{2-}$ and $\mathrm{Cl}^{-}$ions were assayed using an anionic chromatograph (Dionex-ICS 900), equipped with a guard column AG9-HC $(4 \times 50 \mathrm{~mm})$ and a separation column AS9-HC $(4 \times 250 \mathrm{~mm})$. The eluant was a solution of $0.9 \mathrm{mM} \mathrm{Na}_{2} \mathrm{CO}_{3}$, with a flow rate of $0.9 \mathrm{~mL} \mathrm{~min}{ }^{-1}$. For the assay of $\mathrm{NH}_{4}{ }^{+}, \mathrm{Mg}^{2+}, \mathrm{K}^{+}, \mathrm{Ca}^{2+}$ and $\mathrm{Na}^{+}$, a cationic chromatograph was used (Dionex-DX 120), equipped with a guard column CG16 $(5 \times 50 \mathrm{~mm})$ and a separation column CS16 $(5 \times 250 \mathrm{~mm})$. Elution was with $17 \mathrm{mM} \mathrm{H}_{2} \mathrm{SO}_{4}$ at a flow rate of $1.2 \mathrm{~mL} \mathrm{~min}^{-1}$. Detection was by conductivity, and data acquisition and processing were accomplished with a dedicated software program (Chromeleon).

\subsubsection{Osmolality}

Osmolality was determined by measuring the freezing point of the solution with an automatic osmometer (Löser, type 15). Linear correlation between osmolality $(\xi)$ and freezing point gave osmolality using the following equation (Keitaro, 2003):

$\xi=\frac{\Delta T\left({ }^{\circ} \mathrm{C}\right)}{1.858}$

where 1.858 is the freezing point of a solution with an osmolality of 1 osmol.

\section{Results and discussion}

\subsection{Productivity of a continuous culture of C. vulgaris}

C. vulgaris productivity $\left(P_{\mathrm{x}}\right)$ was first determined with a continuous culture in a flat-panel airlift PBR. The conventional medium (Sueoka medium) was supplied to this chemostat, which was kept under continuous illumination with a PFD of $270 \mu \mathrm{mol} \mathrm{m} \mathrm{m}^{-2} \mathrm{~s}^{-1}$ and a temperature and a $\mathrm{pH}$ of $25^{\circ} \mathrm{C}$ and 7.5. A maximal maximum volumetric productivity $\left(P_{\max }\right)$ of $0.76 \mathrm{~kg} \mathrm{~m}^{-3}$ day $^{-1}$ was obtained for an optimal dilution rate $\left(D_{\text {opt }}\right)$ close to 0.68 day $^{-1}$ (Fig. 2). For each experiment, the medium composition was analyzed to make 


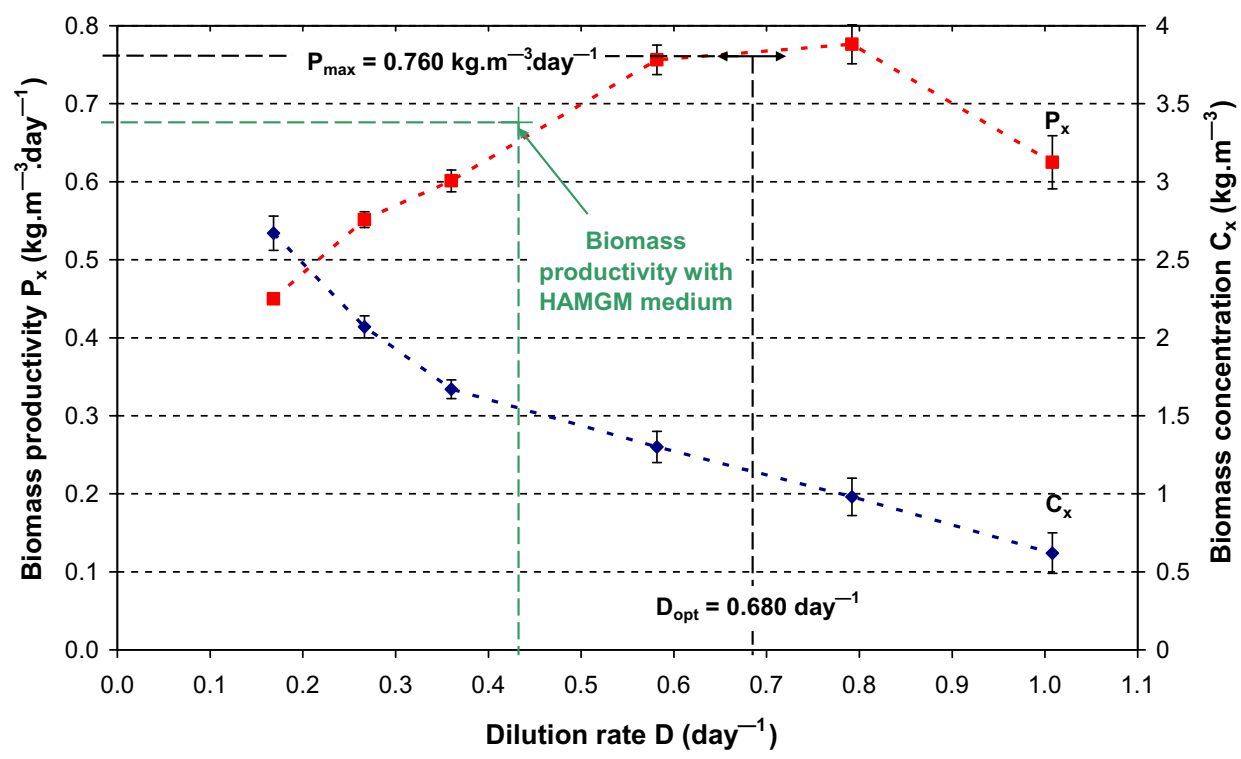

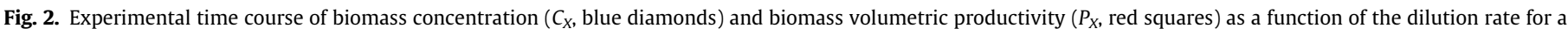

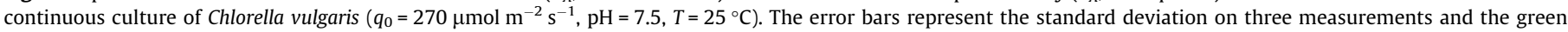

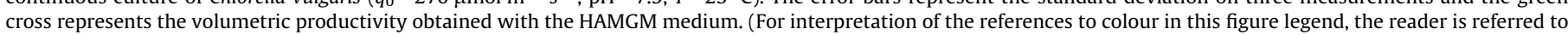
the web version of this article.)

sure there was no mineral limitation that would give light-limited conditions, where only light limits growth, as described by Cornet and Dussap (2009) and Pruvost et al. (2011).

As discussed by Takache et al. (2010), as soon as values of the dilution rate are higher than optimal $\left(D>0.68\right.$ day $^{-1}$ here), light transmission occurs across the culture volume because of the too-low biomass concentrations, leading to the so-called "kinetic regime". Besides a lower productivity, this results in an unstable regime with a risk of culture wash-out. Thus in order to facilitate further experiments to investigate the long-term stability of the process, the PBR was run with a dilution rate below the optimal value, around $0.40 \mathrm{day}^{-1}$ for subsequent recycling experiments. The corresponding biomass productivity was $0.64 \mathrm{~kg} \mathrm{~m}^{-3} \mathrm{day}^{-1}$ with a corresponding biomass concentration in the PBR of $1.5 \mathrm{~g} \mathrm{~L}^{-1}$ (Fig. 2).

\subsection{Culture medium recycling with conventional medium}

Recycling experiments were conducted for eight weeks ( 56 days) by harvesting and recycling the medium twice a week. During this period, 16 harvests and medium recycling processes were performed, and the feeding bottle was renewed six times (i.e. 56 days $/ \tau_{\mathrm{F}}$ ). Fig. 3 represents the time course of biomass concentration, biomass productivity, and total chlorophyll content obtained with cultures fed by the recycled conventional medium. Constant biomass productivity was maintained for the total duration of the experiment (around $0.50 \mathrm{~kg} \mathrm{~m}^{-3} \mathrm{day}^{-1}$ ). Biomass quality seemed unaffected, the total chlorophyll content averaged $5.5 \%$ with a relative standard deviation of only $0.4 \%$. Each individual pigment category ( $\mathrm{Chl}-\mathrm{a}, \mathrm{Chl}-\mathrm{b})$ was stable, as well as the absorbance ratio $\left(A_{480} / A_{665}\right)$ linked to carotenoid and chlorophyll

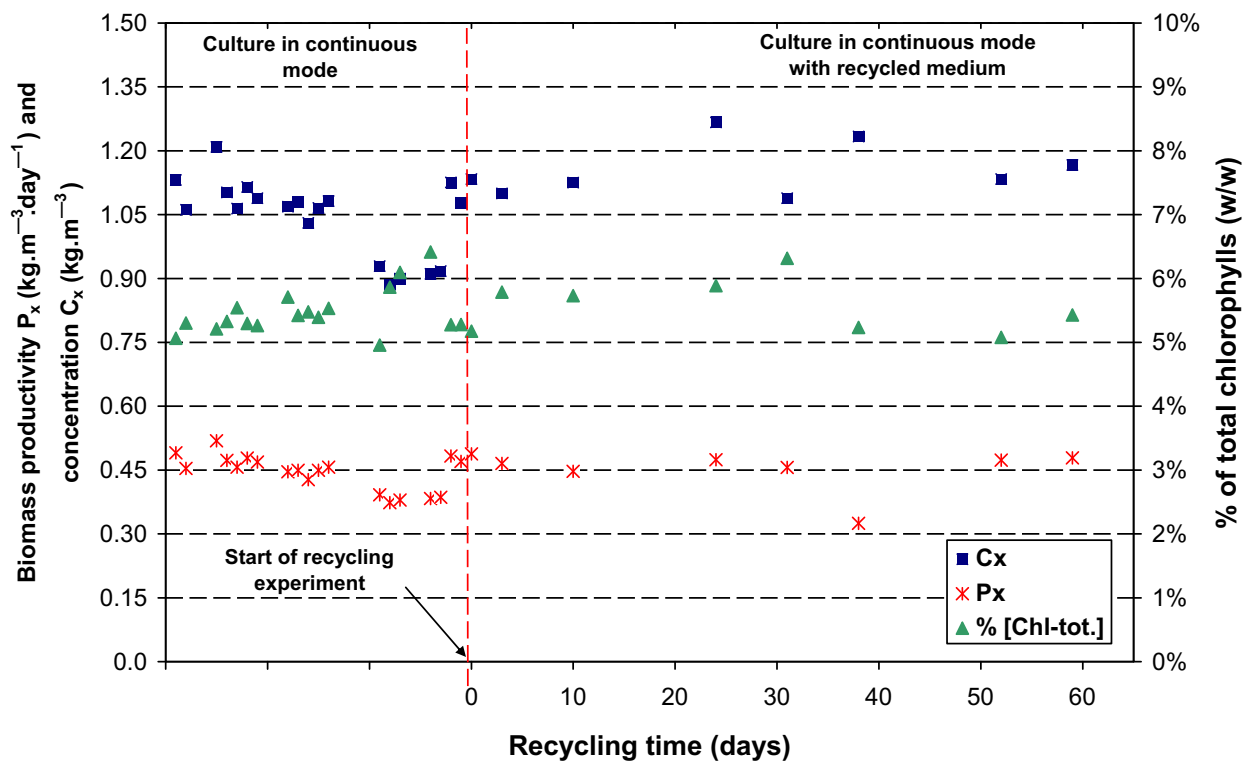

Fig. 3. Time course of biomass concentration and productivity and total chlorophyll content during recycling of the Chlorella vulgaris conventional growth medium. 
contents, which ranged here between 0.74 and 0.78 (results not shown). Although some authors have observed the presence of inhibitors in culture medium, inhibition or a growth rate decrease were not observed in the present experiments, likely due to the fact that growth inhibition seems more important in the case of high cells density cultures. In fact, inhibitory activity was observed for biomass concentration ranging between 6 and $7 \mathrm{~g} \mathrm{~L}^{-1}$ (Richmond, 2004; Richmond and Zou, 1999), whereas in the present case biomass concentration remained moderated $\left(C_{X}=1.5 \mathrm{~g} \mathrm{~L}^{-1}\right)$. Although the microalgal culture seemed to be in steady-state throughout the 16 recycles, a regular increase in total ion concentration and osmolality was observed in the supernatant, with a 4fold increase in osmolality after 8 weeks of recycling due to the accumulation of unassimilated ions (Fig. 4). The main ions involved were chloride $\left(\mathrm{Cl}^{-}\right)$and sodium $\left(\mathrm{Na}^{+}\right)$supplied by the main nutrient sources $\mathrm{Na}_{2} \mathrm{HCO}_{3}$ and $\mathrm{NH}_{4} \mathrm{Cl}$. The concentrations of $\mathrm{Cl}^{-}$and $\mathrm{Na}^{+}$ increased from 14.08 and $10.87 \mathrm{mmol} \mathrm{L}^{-1}$, respectively in the initial feeding medium, to 74.08 and $72.61 \mathrm{mmol} \mathrm{L}^{-1}$ in the final feeding medium, after the eight weeks of recycling, i.e. 5.3- and 6.7-fold increases in concentration. By contrast, there was no significant accumulation in the supernatant of magnesium, calcium or potassium ions. Fig. 4 shows, for example, that $\mathrm{Mg}^{2+}$ disappeared and that $\mathrm{Ca}^{2+}$ and $\mathrm{K}^{+}$accumulated, but in small proportions compared with $\mathrm{Na}^{+}$and $\mathrm{Cl}^{-}$. This observation can be explained by the small quantities of $\mathrm{Mg}^{2+}, \mathrm{Ca}^{2+}$ and $\mathrm{K}^{+}$in the culture medium and by their possible biological consumption by microalgae. At the end of the recycling assay, these minor ions represented only $4 \%$ of the total ion concentration, whereas sodium and chloride ions represented around $90 \%$. The concentrations of the main nutrients (nitrogen, phosphorus and sulfur) were kept almost constant (within 10\%) during the experiments by adjusting their concentrations in the feeding medium at each recycle. The increase in osmolality seems therefore to be due to the accumulation of certain specific ions, such as $\mathrm{Na}^{+}$and $\mathrm{Cl}^{-}$. These results confirmed that conventional culture media, such as Sueoka medium, could lead to a rapid mineral accumulation when the medium is recycled.

\subsection{Stoichiometry of the biomass synthesis}

Although no limitation effects were observed, longer periods of recycling could probably lead to an osmotic stress with possible adverse effects on the biomass production and quality. Such effects have been observed by Alyabyev et al. (2007), who showed that $C$. vulgaris growth was reduced at a $\mathrm{NaCl}$ concentration higher than $500 \mathrm{mM}$. In the present experiments, it would have required 48 weeks before the salts concentration would have increased to more than $500 \mathrm{mM}$. Under such conditions where the productivity $P_{\mathrm{X}}$ is moderate, a culture could maybe be maintained for a long time with no inhibition, although it cannot be excluded that high salinity could have some negative effects. However, for high-productivity cultures, high and inhibiting salts concentrations would appear after a few weeks. To prevent such potential negative effects, a culture medium highly assimilable for $C$. vulgaris was designed to avoid mineral accumulation. For this purpose, the ions that were only weakly consumed $\left(\mathrm{Mg}^{2+}, \mathrm{K}^{+}\right)$or not consumed $\left(\mathrm{Na}^{+}\right)$, were replaced by ammonium $\left(\mathrm{NH}_{4}^{+}\right)$, which is assimilated by microalgae. Ion concentrations were then limited to the strictly metabolic needs of the biomass by measuring ion consumption in standard photosynthetic growth (no mineral limitation). Elementary analysis was performed on biomass from three different batch cultures of $C$. vulgaris. Results were similar and the biomass stoichiometry was computed from average mass contents over the three batches. The results shown in Table 1 are given in terms of mass fraction of each element $i$ analyzed, $x_{\mathrm{m}, i}$. The sum of the
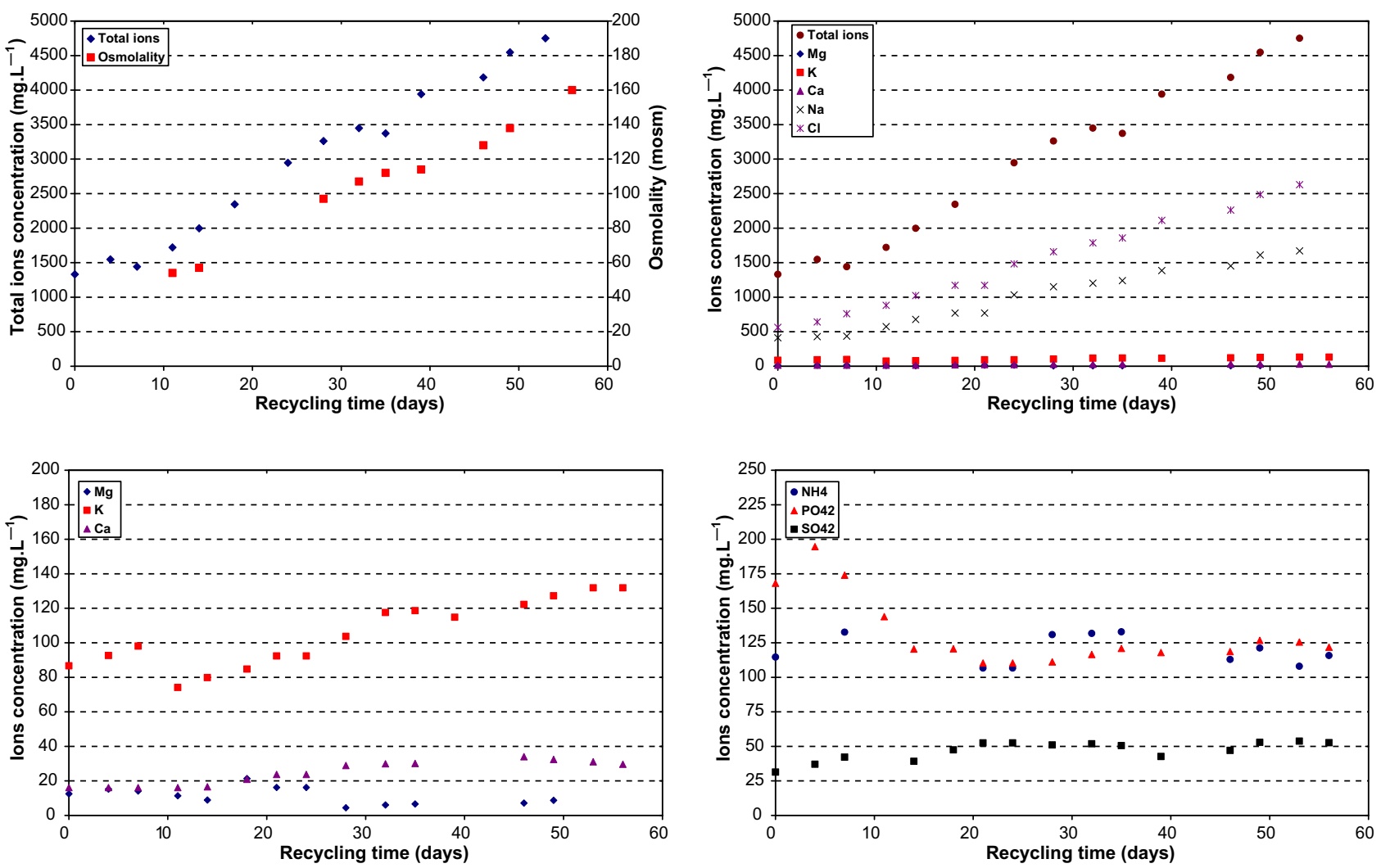

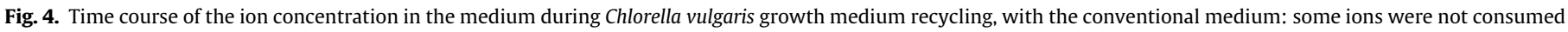
and accumulated during the recycling. 
Table 1

Mass fractions, molecular fractions and molar fractions normalized to carbon, for each element $i$ of Chlorella vulgaris.

\begin{tabular}{|c|c|c|c|c|c|}
\hline Element $(i)$ & Mass fraction $\left(x_{\mathrm{m}, i}\right)(\%)$ & Standard deviation $(\%)$ & Normalized mass fraction $\left(x_{\mathrm{m}, i}^{\prime}\right)(\%)$ & Mole fraction $\left(x_{\mathrm{n}, i}\right)(\%)$ & Mole fraction/mole fraction in $C\left(x_{n, c}\right)$ \\
\hline C & 47.13 & 0.75 & 49.83 & 29.33 & 1 \\
\hline $\mathrm{H}$ & 6.97 & 0.07 & 7.37 & 52.07 & 1.775 \\
\hline 0 & 28.82 & 3.89 & 30.47 & 13.45 & 0.459 \\
\hline $\mathrm{N}$ & 8.11 & 0.90 & 8.57 & 4.33 & 0.148 \\
\hline$S$ & 0.70 & 0.19 & 0.74 & 0.16 & 0.006 \\
\hline$P$ & 1.23 & 0.29 & 1.30 & 0.30 & 0.010 \\
\hline K & 1.06 & 0.39 & 1.12 & 0.20 & 0.007 \\
\hline $\mathrm{Mg}$ & 0.40 & 0.07 & 0.42 & 0.12 & 0.004 \\
\hline $\mathrm{Ca}$ & 0.17 & 0.08 & 0.18 & 0.03 & 0.001 \\
\hline Total & 94.59 & - & 100 & 100 & - \\
\hline
\end{tabular}

fractions of all elements analyzed was not equal to 1 because of experimental errors and also possibly because not all the microelements were analyzed (analyzed elements are summarized in Table 1). To determine a stoichiometric equation for the biomass synthesis from these results, normalized mass fractions $\left(x_{\mathrm{m}, i}^{\prime}\right)$ and mole fraction $\left(x_{\mathrm{n}, i}^{\prime}\right)$ of each element $i$ were computed as:

$x_{\mathrm{m}, i}^{\prime}=\frac{x_{\mathrm{m}, i}}{\sum x_{\mathrm{m}, i}}$,

and

$x_{\mathrm{n}, i}^{\prime}=\frac{\frac{x_{m, i}^{\prime}}{M_{i}}}{\sum_{i} \frac{x_{\mathrm{m}, i}^{\prime}}{M_{i}}}$

where $M_{i}$ is the molecular weight of the element considered.The stoichiometric coefficients for the biomass synthesis were then determined by normalizing the mole fractions of each element $i$ by the carbon mole fraction:

$x_{\mathrm{n}, i / \mathrm{C}}=\frac{x_{\mathrm{n}, i}^{\prime}}{x_{\mathrm{n}, \mathrm{c}}^{\prime}}$

Finally, a stoichiometric equation of $C$. vulgaris growth was established on the basis of the elementary analysis (C, H, O, N, S, P) (Roels, 1983):

$$
\begin{aligned}
& \mathrm{CO}_{2}+0.148 \mathrm{NH}_{4}^{+}+0.006 \mathrm{H}_{2} \mathrm{SO}_{4}+0.010 \mathrm{H}_{3} \mathrm{PO}_{4} \\
& +0.571 \mathrm{H}_{2} \mathrm{O} \stackrel{h v}{\rightarrow} \mathrm{CH}_{1.776} \mathrm{O}_{0.459} \mathrm{~N}_{0.148} \mathrm{~S}_{0.006} \mathrm{P}_{0.010}+1.088 \mathrm{O}_{2}
\end{aligned}
$$

The biomass C-molecular weight $\left(M_{x}\right)$ calculated from the normalized was equal to $24.02 \mathrm{gC} \mathrm{mol}^{-1}$. The stoichiometric equation for biomass synthesis (Eq. (6)) gives an estimate of nutrient requirements from their assimilation in the biomass.

These requirements can also be deduced from ion consumption in the culture medium, estimated as the difference between nutrient concentrations in the inlet (feeding) and outlet (harvest) of the PBR operated in continuous steady-state mode. Nutrient concentrations can be measured, for example, by ionic chromatography (IC) as discussed by Pruvost et al. (2011). Nutrient requirements were computed in this work both by nutrient assimilation by the biomass and by nutrient disappearance from the medium (Table 2). The nutrient requirements estimated from the ionic analysis of the culture medium and the biomass elementary analysis were very close for ammonium, sulfate, phosphate and potassium ions. Minor nutrients, magnesium and calcium requirements computed from accumulation in biomass were lower than those obtained from the measurement of nutrient consumption in batch experiments. As the concentrations of magnesium and calcium ions were very low $\left(<50 \mathrm{mg} \mathrm{L}^{-1}\right)$, this difference can be attributed to insufficient sensitivity of the ionic chromatograph. In addition, decreased magnesium and calcium concentrations in the medium could probably also have been adsorbed onto the external cell surface since, biosorption of these ions by microalgae is a well-known phenomenon (Çetinkaya Dönmez et al., 1999; De-Bashan and Bashan, 2010). As the biomass was abundantly washed with distilled water before elementary analysis, the ions could have desorbed and thus would not have been measured during elementary analysis. This ion biosorption introduced a difference in the requirements calculation between the two methods. However, ionic analysis of the medium and elementary analysis of the biomass provided consistent estimations of the consumption of major nutrients $\left(\mathrm{NH}_{4}{ }^{+}, \mathrm{SO}_{4}{ }^{2-}, \mathrm{PO}_{4}{ }^{-}\right)$. The ionic chromatography measurements also confirmed the absence of significant consumption of $\mathrm{Cl}^{-}$and $\mathrm{Na}^{+}$ions during biomass growth (the negative values being possibly attributable to uncertainties in ionic chromatograph measurement).

\subsection{Development of the HAMGM medium}

The guideline for the development of a highly assimilable minimal growth medium was to replace unassimilated ions by ammonium $\left(\mathrm{NH}^{4+}\right)$, which can be assimilated by $C$. vulgaris. The concentrations of the main nutrients $\left(\mathrm{NH}^{4+}, \mathrm{SO}_{4}{ }^{2-}, \mathrm{PO}_{4}{ }^{3-}\right)$ needed to reach a given biomass concentration in the PBR were estimated

Table 2

Nutrient disappearance in the medium (determined by ionic chromatography) compared with accumulation of the nutrients in the biomass (determined by elementary analysis) for Chlorella vulgaris. The results are normalized to 1 mol of biomass.

\begin{tabular}{lllc}
\hline Ion & $\begin{array}{l}\text { Accumulation of nutrients } \\
\text { in the biomass }\left(\mathrm{mmol} \mathrm{mol}_{x}{ }^{-1}\right)\end{array}$ & $\begin{array}{l}\text { Disappearance of nutrients } \\
\text { in the medium }\left(\mathrm{mmol} \mathrm{mol}_{x}{ }^{-1}\right)\end{array}$ & $\begin{array}{l}\text { Deviation between accumulation } \\
\text { and disappearance }(\%)\end{array}$ \\
\hline $\mathrm{NH}_{4}{ }^{+}$ & 147.6 & 146.8 & 0.48 \\
$\mathrm{SO}_{4}{ }^{2-}$ & 5.56 & 6.01 & 8.09 \\
$\mathrm{PO}_{4}{ }^{3-}$ & 10.08 & 8.60 & 14.7 \\
$\mathrm{~K}^{+}$ & 5.79 & 5.79 & 0.07 \\
$\mathrm{Mg}^{2+}$ & 3.80 & 8.01 & 110 \\
$\mathrm{Ca}^{2+}$ & 0.92 & 2.34 & 155 \\
$\mathrm{Cl}^{-}$ & - & -1.56 & - \\
$\mathrm{Na}^{+}$ & - & -1.78 & - \\
\hline
\end{tabular}


from the biomass synthesis equation. Mass yields of each element $i$ $\left(Y_{i} / C_{x}\right)$ defined as the ratio of the amount of the element consumed to the amount of the biomass produced were deduced from Eq. (6):

$Y_{i / C x}=\frac{\text { mass of element } i \text { consumed }}{\text { mass of biomass produced }}=\beta_{i} \times \frac{M_{i}}{M_{X}}$

with $\beta_{i}$, the stoichiometric coefficient of $i$ in the biomass synthesis equation, $M_{i}$ the molecular weight of $i$, and $M_{x}$ the molecular weight of the biomass.

The following values of mass yields in nitrogen, sulfur and phosphate were obtained: $Y_{\mathrm{NH}^{+}}{ }^{+} / C_{X}=0.112 \mathrm{~g} \mathrm{~g}_{X}{ }^{-1}, Y_{\mathrm{SO} 4}{ }^{2-} /{ }^{2} X=0.025$ $\mathrm{g} \mathrm{g}_{X}{ }^{-1}, Y_{\mathrm{PO} 4}{ }^{3-} / C_{X}=0.040 \mathrm{gg}_{X}{ }^{-1}$. These mass yields were used to determine the stoichiometric amounts of major nutrients needed to produce a biomass with a desired concentration (here, $1.7 \mathrm{~g} \mathrm{~L}^{-1}$ ). For each element $i$, the mass yields were deduced from the following mass balance equation:

$$
\left\{\begin{array}{l}
\text { Accumulation of element } i \\
\text { in biomass }
\end{array}\right\}=\left\{\begin{array}{l}
\text { Element } i \text { drained off } \\
\text { from the medium }
\end{array}\right\}
$$

$Q \cdot C_{X} \cdot Y_{i / C X}=Q \cdot\left(C_{i}^{\text {in }}-C_{i}^{\text {out }}\right)$

where $Y_{i / C_{X}}, M_{X}$ and $M_{i}$ are the same as in Eq. (7), $Q$ the inlet medium flow rate, $C_{X}$ the biomass concentration, and $C_{i}^{\text {in }}$ and $C_{i}^{\text {out }}$ the concentrations of element $i$ at the inlet and outlet of the PBR. $C_{i, \text { min }}$ was defined as the minimum inlet mass concentration of nutrient $i$ corresponding to the minimal requirements with no limitation $\left(C_{i, \min }=C_{i}^{\text {in }}\right.$ and $\left.C_{\mathrm{i}}^{\text {out }}\right)$. The minimal concentrations of the minor nutrients $\left(\mathrm{K}^{+}, \mathrm{Mg}^{2+}, \mathrm{Ca}^{2+}\right)$ were computed with the more precise data from ionic chromatography analyses, which takes into account the proportion of ions adsorbed onto the biomass (Table 2). The concentrations $C_{i}$ of main and minor nutrients used to design the HAMGM medium were obtained by considering an excess of $30 \%$ with respect to the minimal concentration to avoid any mineral limitation $\left(C_{i}=1.3 \times C_{i, \min }\right)$.

In contrast to major nutrients, the quantification of micronutrient needs (trace elements, usually supplied by Hutner's solution) is very difficult due to their very small concentrations. However Cogne et al. (2003) demonstrated that it is possible to reduce the quantities of these microelements with no impact on growth of Arthrospira platensis. A series of tests was thus performed on continuous cultures with decreasing quantities of Hutner's solution to determine the minimal concentration of trace element acceptable (i.e. that did not slow the microalgae growth), and thus to limit their accumulation during recycling. Half the original concentration of the salts in Hutner's solution was found to be sufficient to conduct a continuous culture up to a biomass concentration of $1.7 \mathrm{~g} \mathrm{~L}^{-1}$. This was verified with a continuous culture maintained for several weeks. Thus a $0.5 \mathrm{~mL} \mathrm{~L}^{-1}$ Hutner's solution was used in the composition of the HAMGM instead of the usual $1 \mathrm{~mL} \mathrm{~L}^{-1}$.

Once the desired nutrient composition of the HAMGM medium $\left(\mathrm{NH}_{4}{ }^{+}, \mathrm{HCO}_{3}{ }^{-}\right)$was known, the required concentrations of salts was determined. Nitrogen was supplied as ammonium bicarbonate $\left(\mathrm{NH}_{4} \mathrm{HCO}_{3}\right)$, so that the bicarbonate $\left(\mathrm{HCO}_{3}{ }^{-}\right)$mole concentration was equal to that of the ammonium. Phosphate was partly supplied as potassium phosphate $\left(\mathrm{KH}_{2} \mathrm{PO}_{4}\right)$ to meet the potassium ion intake needs and the rest as ammonium phosphate $\left(\left(\mathrm{NH}_{4}\right)_{2}\right.$ $\left.\mathrm{HPO}_{4}\right)$. The sulfur and magnesium requirements were met with magnesium sulfate $\left(\mathrm{MgSO}_{4} \cdot 7 \mathrm{H}_{2} \mathrm{O}\right)$. Calcium was supplied as calcium chloride $\left(\mathrm{CaCl}_{2}\right)$.

The HAMGM medium composition obtained in this way is given in Tables 3 and 4 . The total ion concentration of HAMGM is $1.57 \mathrm{~g} \mathrm{~L}^{-1}$, as compared $4.10 \mathrm{~g} \mathrm{~L}^{-1}$ for the more concentrated conventional medium, corresponding to a $62 \%$ decrease in mass in initial nutrient supply. Although the cost of nutrients is probably
Table 3

HAMGM medium composition developed for Chlorella vulgaris. This medium provides a maximum biomass concentration of $1.7 \mathrm{~g} \cdot \mathrm{L}^{-1}$.

\begin{tabular}{lcl}
\hline Nutrient & $C\left(\mathrm{mg} \mathrm{L}^{-1}\right)$ & $C\left(\mathrm{mmol} \mathrm{L}^{-1}\right)$ \\
\hline $\mathrm{NH}_{4} \mathrm{HCO}_{3}$ & 1099 & 13.9 \\
$\mathrm{MgSO}_{4} \cdot 7 \mathrm{H}_{2} \mathrm{O}$ & 187 & 0.76 \\
$\left(\mathrm{NH}_{4}\right)_{2} \mathrm{SO}_{4}$ & 0 & 0 \\
$\mathrm{KH}_{2} \mathrm{PO}_{4}$ & 72.5 & 0.53 \\
$\left(\mathrm{NH}_{4}\right)_{2} \mathrm{HPO}_{4}$ & 164 & 1.24 \\
$\mathrm{CaCl}_{2} \cdot 2 \mathrm{H}_{2} \mathrm{O}$ & 50 & 0.22 \\
Hutner & $0.5 \mathrm{~mL} \mathrm{~L}^{-1}$ & \\
\hline
\end{tabular}

Table 4

Ion concentrations in the HAMGM medium.

\begin{tabular}{lcc}
\hline Nutrient & $C\left(\mathrm{mg} \mathrm{L}^{-1}\right)$ & $C\left(\mathrm{mmol} \mathrm{L}^{-1}\right)$ \\
\hline $\mathrm{NH}_{4}{ }^{+}$ & 295 & 16.4 \\
$\mathrm{SO}_{4}{ }^{2-}$ & 73 & 0.76 \\
$\mathrm{PO}_{3}{ }^{2-}$ & 169 & 1.76 \\
$\mathrm{HCO}_{3}{ }^{-}$ & 848 & 13.9 \\
$\mathrm{Mg}^{2+}$ & 18.2 & 0.76 \\
$\mathrm{~K}^{+}$ & 21.1 & 0.54 \\
$\mathrm{Cl}^{-}$ & 15.4 & 0.43 \\
$\mathrm{Ca}^{2+}$ & 8.8 & 0.22 \\
Total & 1449 & 34.77 \\
\hline
\end{tabular}

higher for HAMGM, the decrease in initial nutrient supply would allow economical saving. As an example, considering nutrients prices for the biggest packaging proposed by a lab-scale nutrients supplier ( $5 \mathrm{~kg}$ or $25 \mathrm{~kg}$ ), the economical saving was estimated around 50\%. The HAMGM medium fulfilled the purpose of minimizing nutrient supply and losses, and accumulation of the non-assimilated ions and water consumption (WC) by $77 \%$ during medium recycling. Without recycling, the 8 -week culture needed 24.2 L of water (continuous culture with $D=0.43$ days $^{-1}$ and PBR volume $=1 \mathrm{~L}$ ). With recycling HAMGM medium, water consumption (WC) was reduced to $5.6 \mathrm{~L}$. The initial feeding medium volume (4 L) was four times greater than the PBR volume (1 L) and at every recycle, water loss (WL) due to evaporation and harvesting, represented $10 \%$ of PBR volume and was determined by Eq. (10).

$\mathrm{WL}=0.1 \times$ volume of the $\mathrm{PBR} \times$ number of recycles

$\mathrm{WC}=$ Initial feeding medium volume $+\mathrm{WL}$

\subsection{Validation of the HAMGM medium}

To check that the HAMGM medium could ensure the same productivity as conventional medium, C. vulgaris was grown in HAMGM and conventional medium under the same culture conditions (continuous culture with $D=0.43$ day $^{-1}, q_{0}=270 \mu \mathrm{mol} \mathrm{m}^{-2} \mathrm{~s}^{-1}$, $\mathrm{pH}=7.5, T=25^{\circ} \mathrm{C}$ ). The volumetric biomass productivity obtained at steady-state was around $0.68 \mathrm{~kg} \mathrm{~m}^{-3} \mathrm{day}^{-1}$ (Fig. 2), very close to that obtained with the conventional medium (5.8\% of deviation). $C$. vulgaris culture in HAMGM medium was thus considered as validated. In a final step, the recycling of $C$. vulgaris growth medium was tested using HAMGM medium (Fig. 5). A constant productivity was maintained throughout the eight weeks of the recycling procedure. More interestingly, ion accumulation was clearly reduced in comparison with the conventional medium. As expected, ion concentrations in the PBR effluent remained almost constant throughout the recycling experiment, with values of total ion concentration ranging between 250 and $350 \mathrm{mg} \mathrm{L}^{-1}$. The nutrient feeding was limited to the physiological needs of $C$. vulgaris. The 


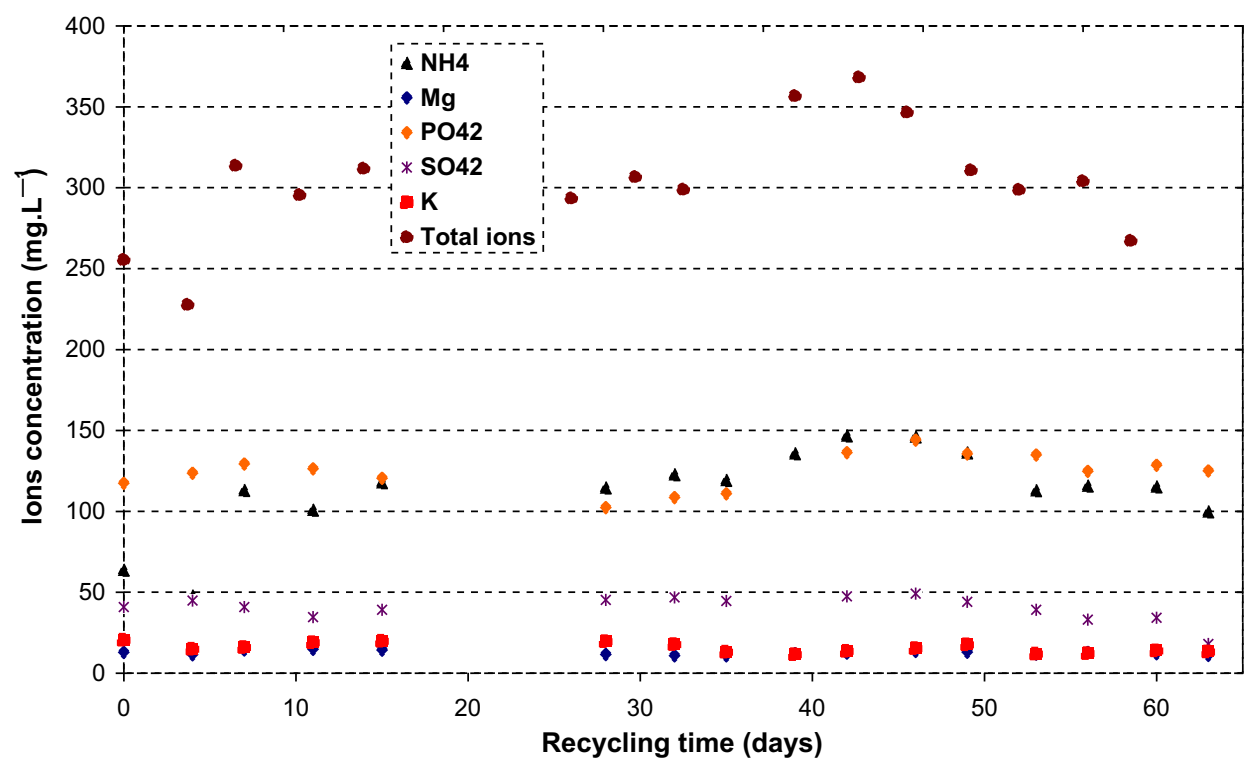

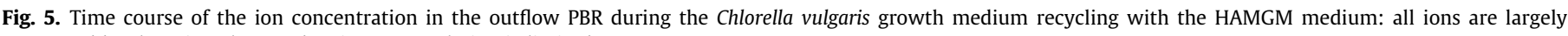
consumed by the microalgae and so ion accumulation is limited.

small fluctuations in concentration observed were attributable to slight variations in the supply pump during the experiment.

\section{Conclusion}

Controlling and reducing nutrient intakes in large-scale continuous cultures are key economic and ecologic issues. A highly assimilable minimal growth medium (HAMGM) was developed and validated for $C$. vulgaris by running continuous long-term cultures. The initial nutrient inputs were limited to the physiological requirements of microalgae, and unassimilated ions were replaced by ammonium $\left(\mathrm{NH}_{4}^{+}\right)$. When HAMGM medium was recycled, ion accumulation was thus limited and very close biomass productivities were achieved with conventional and HAMGM media. Water consumption was reduced by around $77 \%$ and nutrients cost saving estimated around $50 \%$.

\section{Acknowledgments}

The authors thank Hélène Marec and Jean-Luc Hauser for photobioreactor design and technical support.

\section{References}

Alyabyev, A.J., Loseva, N.L., Gordon, L.K., Andreyeva, I.N., Rachimova, G.G., Tribunskih, V.I., Ponomareva, A.A., Kemp, R.B., 2007. The effect of changes in salinity on the energy yielding processes of Chlorella vulgaris and Dunaliella maritima cells. Thermochimica Acta 458, 65-70.

Benemann, J.R., 2009. Microalgal biofuels: a brief introduction. In: http:// www.adelaide.edu.au/biogas/renewable/biofuels_introduction.pdf (Ed.).

Borowitzka, M.A., 1999. Commercial production of microalgae: ponds, tanks, tubes and fermenters. Journal of Biotechnology 70, 313-321.

Çetinkaya Dönmez, G., Aksu, Z., Öztürk, A., Kutsal, T., 1999. A comparative study on heavy metal biosorption characteristics of some algae. Process Biochemistry 34 885-892.

Chisti, Y., 2007. Biodiesel from microalgae. Biotechnology Advances 25, 294-306.

Cogne, G., Lehmann, B., Dussap, C.-G., Gros, J.-B., 2003. Uptake of macrominerals and trace elements by the cyanobacterium Spirulina platensis (Arthrospira platensis PCC 8005) under photoautotrophic conditions: Culture medium optimization. Biotechnology and Bioengineering 81, 588-593.

Cornet, J.F., Dussap, C.G., 2009. A Simple and reliable formula for assessment of maximum volumetric productivities in photobioreactors. Biotechnology Progress 25, 424-435.

De-Bashan, L.E., Bashan, Y., 2010. Immobilized microalgae for removing pollutants: review of practical aspects. Bioresource Technology 101, 1611-1627.
Fogg, G.E., 1966. The extracellular products of algae. Oceanography and Marine Biology: An Annual Review 4, 195-212.

Fogg, G.E., 1971. Extracellular products of algae in freshwater. Archiv für hydrobiologie 5, 1-25.

Harris, E.H., 2009. The Chlamydomonas Source Book. Introduction to Chlamydomonas and its Laboratory Use. Academic Press Inc., New York.

Harun, R., Singh, M., Forde, G.M., Danquah, M.K., 2010. Bioprocess engineering of microalgae to produce a variety of consumer products. Renewable and Sustainable Energy Reviews 14, 1037-1047.

Hutner, S.H., Provasoli, L., Schatz, A., Haskins, C.P., 1950. Some approaches to the study of the role of metals in the metabolism of microorganisms. Proceedings of the American Philosophical Society 94, 152-170.

Ikawa, M., 2004. Algal polyunsaturated fatty acids and effects on plankton ecology and other organism. UNH Center for Freshwater Biology Research 6, 17-44.

Keitaro, K., 2003. Theoretical and experimental studies on freezing point depression and vapor pressure deficit as methods to measure osmotic pressure of aqueous polyethylene glycol and bovine serum albumin solutions. Biophysical Chemistry 104, 171-188.

Mata, T.M., Martins, A.A., Caetano, N.S., 2010. Microalgae for biodiesel production and other applications: A review. Renewable and Sustainable Energy Reviews 14, 217-232.

Muller-Feuga, A., 2000. The role of microalgae in aquaculture: situation and trends. Journal of Applied Phycology 12, 527-534.

Pruvost, J., Van Vooren, G., Cogne, G., Legrand, J., 2009. Investigation of biomass and lipids production with Neochloris oleoabundans in photobioreactor. Bioresource Technology 100, 5988-5995.

Pruvost, J., Van Vooren, G., Le Gouic, B., Couzinet-Mossion, A., Legrand, J., 2011. Systematic investigation of biomass and lipid productivity by microalgae in photobioreactors for biodiesel application. Bioresource Technology 102, 150158.

Pulz, O., Gross, W., 2004. Valuable products from biotechnology of microalgae. Applied Microbiology and Biotechnology 65, 635-648.

Reisner, G.S., Gering, R.K., Thompson, J.F., 1960. The Metabolism of Nitrate and Ammonia by Chlorella. Plant Physiology 35, 48-52.

Richmond, A., 2004. Handbook of Microalgal Culture: Biotechnology and Applied Phycology. Blackwell Sciences Ltd., Oxford.

Richmond, A., Zou, N., 1999. Efficient utilisation of high photon irradiance for mass production of photoautotrophic micro-organisms. Journal of Applied Phycology $11,123-127$.

Ritchie, R., 2006. Consistent sets of spectrophotometric chlorophyll equations for acetone, methanol and ethanol solvents. Photosynthesis Research 89, 27-41.

Robertson, P., Fong, J., 1940. Studies on chlorella vulgaris II. Further evidence that chlorella cells form a growth-inhibiting substance. American Journal of Botany 27, 431-436.

Roels, J.A., 1983. Energetics and Kinetics Ion Biotechnology. Elsevier Biomedical Press, Amsterdam.

Rossi, N., Derouiniot-Chaplain, M., Jaouen, P., Legentilhomme, P., Petit, I., 2008. Arthrospira platensis harvesting with membranes: Fouling phenomenon with limiting and critical flux. Bioresource Technology 99, 6162-6167.

Schuler, J.F., Diller, V.M., Kersten, H.J., 1952. Preferential assimilation of ammonium ion by Chlorella vulgaris. Plant Physiology 28, 299-303.

Spolaore, P., Joannis-Cassan, C., Duran, E., Isambert, A., 2006. Commercial applications of microalgae. Journal of Bioscience and Bioengineering 101, 8796. 
Sueoka, N., 1960. Mitotic replication of deoxyribonucleic acid in Chlamydomonas reinhardi. Proceedings of the National Academy of Sciences $46,83-91$

Takache, H., Christophe, G., Cornet, J.-F., Pruvost, J., 2010. Experimental and theoretical assessment of maximum productivities for the microalgae
Chlamydomonas reinhardtii in two different geometries of photobioreactors. Biotechnology Progress 26, 431-440.

Wu, J.T., Chiang, Y.R., Huang, W.Y., Jane, W.N., 2006. Cytotoxic effects of free fatty acids on phytoplankton algae and cyanobacteria. Aquatic Toxicology 80, 338345. 